\title{
SUJECION Y CARENCIA. CAMBIO Y CONTINUISMO EN LOS HOSPITALES DE BUENOS AIRES (1870-1900)
}

\section{Ricardo González Leandri}

\section{BUENOS AIRES EN LA SEGUNDA MITAD DEL SIGLO XIX: MODERNIZACION Y CAMBIO SOCIAL}

A partir de la segunda mitad del siglo XIX, la República Argentina -en especial las regiones de Buenos Aires y Santa Fé- comenzó a redefinir su inserción en el sistema económico mundial, convirtiéndose en un dinámico productor de bienes primarios de exportación.

Las demandas de este sistema en pleno crecimiento económico «hacia afuera» - tanto en lo referido al régimen agropecuario como a la instalación y construcción de ferrocarriles y obras públicas- movilizaron la inversión de cuantiosos capitales y estimularon la llegada al país de grandes contingentes migratorios (1).

Este proceso de crecimiento que comenzaba en forma tenue se aceleró marcadamente a partir de la década de 1880 , y fueron sus consecuencias más notables el aumento de la población y el rápido crecimiento urbano, en especial el de Buenos Aires. 
Para explicar el futuro de la sociedad argentina, es esencial aclarar la índole de esta transformación que excedió en mucho el mero aumento de las dimensiones físicas de la ciudad: el tejido social mismo llegó a transformarse radicalmente, haciéndose a su vez más denso y complejo. La élite tradicional, en el proceso de gestación «desde arriba» de aquellos cambios sociales, se modificó también a sí misma, hasta el punto de llegar a convertirse en una verdadera oligarquía terrateniente, comercial y financiera. Por debajo suyo, los nuevos trabajadores de origen europeo, junto a los grupos criollos preexistentes, dieron origen a una vasta masa popular, a la que José Luis Romero denominó «el conglomerado criollo-inmigratorio» (2).

La irrupción masiva de aquel vasto sector de "pobres indisciplinados» escandalizó a muchos contemporáneos. Sus testimonios artículos de prensa, manifestaciones de gobernantes y la literatura de la época- muestran que lo fundamental en dicho asombro fue que la ciudad devino irreconocible a los ojos de la élite social a causa de la pérdida de sus rasgos tradicionales de "gran aldea" (3).

Esta novedad - sin duda alarmante para los sectores sociales hegemónicos- llevó a sus miembros más conspicuos al intento de implementar medidas eficaces de contención de aquella masa social que veían como peligrosa y que, con su sola presencia, desafiaba al orden tradicional. La famosa "cuestión social», con su nítido contenido de «lucha de clases», comenzaba así a ser atisbada por algunos, aunque sólo a principios del siglo xx iba a mostrarse en toda su plenitud.

\section{EL CONTROL SOCIAL Y LAS NECESIDADES}

El nuevo control previsto para contener al conglomerado criolloinmigratorio se apoyó en la intervención creciente de un Estado que lograría más adelante consolidarse como tal, guiado por la mano hábil de aquella élite social autotransformada (4).

Dentro del nuevo esquema previsto, los crecientes sectores populares debían ser controlados en sus desbordes - políticos, sociales, y «morales»-y virtualmente "transformados» en su composición social. Para ello se modernizaron importantes aspectos judiciales y represivos, implementándose también nuevas estrategias en las áreas educativa, sanitaria y filantrópica.

Pero lo verdaderamente novedoso en este gran proyecto renovador fue el intento de aplicación de la idea (con importantes antecedentes 
en viejas teorías filantrópicas) de que los sectores populares, en general, y los pobres en particular pueden ser controlados más eficazmente regulando y reorientando sus necesidades que con la represión de sus manifestaciones públicas más extremas (5).

Poner en práctica esta idea, fue lo que llevó a que áreas en continua redefinición como la moral, la salud y el saneamiento urbano, comenzaran a ser comprendidas, al menos de forma implícita, en sus contenidos políticos. Este importante proceso condujo a que nuevos personajes técnicos - médicos y también arquitectos-comenzaran a tener una creciente influencia, tan to en el diseño como en la puesta en práctica de las nuevas estrategias políticas.

Siguieron sin duda siendo utilizados algunos de los viejos mecanismos e instituciones de control social que dejaban traslucir los aspectos más paternalistas de la sociedad (el Hospital General, determinadas formas de reclusión y ciertas categorías de limosna). Pero fueron reemplazados paulatinamente, superando a veces tenaces resistencias, por otros más novedosos, que implicaban en muchos casos una mayor intervención estatal (6).

Estas nuevas intervenciones, con su afán de eficacia, categorización (por ejemplo diferenciar pobres de enfermos) y racionalidad, se inspiraron en el positivismo y en el darwinismo, con su énfasis en lo biológico como paradigma para interpretar la realidad social. Ayudaron también a conformar un clima de ideas que legitimó en forma plena a la figura del médico como personaje idóneo y especializado para promover y dirigir nuevas formas de política social que tuvieron como principales destinatarios a los sectores populares.

En este proceso global y en el más acotado de ayudar a la delimitación de un campo específico de los «cuidados» de la salud, cumplió un papel fundamental un grupo de médicos nucleados alrededor de la $R e$ vista Médico-Quirúrgica, sostenedores férreos de las orientaciones del Higienismo de inspiración francesa (país en el que casi todos ellos habían estudiado).

Estos mismos médicos higienistas, debido fundamentalmente a su iniciativa y a sus funciones polivalentes como técnicos, políticos y funcionarios, lograron un mayor disciplinamiento de la vida urbana a través de la intervención municipal. Su énfasis regulador se orientó hacia los aspectos higiénicos, pero también hacia los «morales» puesto que en Buenos Aires -ciudad con amplia proporción de migrantes solosla lucha contra las enfermedades venéreas requirió un rígido control de la prostitución. 
Pertenecen a iniciativas suyas los estrictos planes tendentes a erradicar la prostitución clandestina, las periódicas campañas de clausura de bares y cafés con camareras, la reglamentación, inspección y desalojo de "conventillos» y prostíbulos, la asistencia domiciliaria y el saneamiento hospitalario.

Nuevas maneras de plantear la intervención médica lograron desarraigar aspectos importantes de la concepción de asistencia básicamente caritativa, hegemónica hasta entonces. Estas nuevas actitudes, trataban ahora de combinar los beneficios promovidos por la instalación de adecuados servicios sanitarios con meticulosos registros estadísticos utilizables como herramienta de planeamiento y previsión.

\section{LA UTOPIA DECENTRALIZADORA Y EL TRIUNFO DEL HOSPITAL}

La estrategia higienista -fundamental debido al papel de vanguardia- de dicho grupo, tuvo también un fuerte contenido utópico. Su afán de controlar preventivamente al conjunto de la población y su creencia en la posibilidad de lograr un medio urbano absolutamente aséptico, fueron a veces de difícil implementación práctica.

Una de las ideas más importantes sostenidas por ese conjunto de médicos influyentes, fue la de descentralizar las ayudas sociales y los controles sanitarios (7). En su afán de incentivo a las ayudas a domicilio y de establecimiento de casas de socorro barriales, no escatimaron críticas al sistema del Hospital General. Esta crítica fue fundamental debido a que sobre dicha institución, y en especial sobre su ambigua función de reclusorio y de depósito en última instancia, se basó toda la estrategia caritativa de control y ayuda social que se venía poniendo en práctica, a pesar de las críticas de una corporación médica incipiente, y con escaso poder social hasta entonces.

Al Hospital General se le criticaba su ineficacia, su alto coste, su intervención sólo en las fases terminales y su concepción «estática». Lo que se requería ahora, según las corrientes en boga, era que los especialistas se anticiparan, dirigiéndose ellos mismos a los centros de la enfermedad y la miseria, concepto que, dado el clima general de ideas de la época, daría motivo a múltiples experimentos literarios con éxito desigual.

Guillermo Rawson, en su famoso estudio sobre las casas de inquilinato, se había expresado claramente en tal sentido:

Asclepio-I-1990 
«No basta construir hospitales y asilos de pobres y mendigos; no basta acudir con los millones para subvenir a estos infortunios accidentales en aquella clase deprimida de la sociedad. Es necesario ir más allá, es preciso buscar al pobre en su alojamiento y mejorar las condiciones higiénicas de su hogar levantando así su vigor físico y moral» (8).

Con esta idea, como con otras concepciones higienistas «fuertes», en especial aquéllas vinculadas a la ayuda domiciliaria y a los cambios de ejes en la atención médica, pasó lo que con muchas ideas revolucionarias: fueron aplicadas en forma parcial y dentro de un paradigma de control y transformación social, distinto del marco que las originara.

De esta manera el Hospital, por múltiples causas -sociales, presupuestarias y fundamentalmente simbólicas- siguió siendo con los higienistas impulsores de la Asistencia Pública e incluso sin ellos, el eje central de las políticas sanitarias. Las ideas alternativas como las casas de socorro y la asistencia domiciliaria, caballo de batalla de la prédica higienista, quedaron empequeñecidas ante la importancia simbólica del Hospital como institución, y sólo fueron aplicadas con el tiempo como meras acciones complementarias.

El triunfo del Hospital representó la gran derrota de ciertos médicos y funcionarios que tanto éxito tuvieron en otras cuestiones vinculadas al saneamiento urbano y al control social de la pobreza. Así fue como la idea de «controlar a partir de las necesidades» sólo pudo ser aplicada parcialmente.

La derrota de aquel proyecto descentralizador, el más importante de todos los elaborados en el siglo XIX, tuvo su origen en la frágil alianza establecida entre la élite política y los funcionarios higienistas, para llevar a cabo sus estrategias fuertemente contradictorias en muchos aspectos. Una de las partes veía al Hospital como gran símbolo de poder (de ahí la importancia capital que en su construcción y en los presupuestos se otorgaba a las cuestiones de ornato, tan criticadas por los médicos). Esta misma élite estaba dispuesta a modernizar la sociedad, pero sólo hasta donde las reglas del mercado lo demandaran. El cuidado de la salud de los trabajadores y aun el control y puesta en vereda de este grupo productor eran vistos como meros elementos reguladores del funcionamiento sin trabas serias de un mercado de trabajo. Todo lo que excediera esta intención, dadas las facilidades que ofrecía Europa como proveedora continua de mano de obra barata, no era estimado. 
Como consecuencia del afianzamiento de ese todopoderoso sector social, los médicos higienistas fueron quedando aislados en la implementación de sus ideas más avanzadas, aquellas que podían representar, más allá de su mero control, una mejora radical en las condiciones de vida de los sectores populares. Muchas de estas ideas tuvieron que esperar épocas mejores para ser aplicadas. Otras no lo fueron nunca.

Como testigo de este fracaso parcial, pero lógico, queda el testimonio solitario de las permanentes quejas de los médicos y los funcionarios acerca del desinterés estatal y de la falta crónica de recursos para atender a la salud de la población trabajadora en una sociedad en muchos aspectos opulenta.

La evolución misma de muchos de estos médicos, y en especial la de sus jóvenes discípulos, que viraron hacia posturas ideológicas más fuertemente contestatarias, muestra las serias limitaciones que existían entonces para poner en práctica desde el Estado políticas más acordes con las necesidades de aquel conglomerado criollo-inmigratorio.

\section{POR SIEMPRE EL HOSPITAL: NUEVOS MECANISMOS DE CONTROL Y PERSISTENCIA DE VIEJOS PROBLEMAS}

El hospital continuó siendo, aun después de la creación de la Asistencia Pública, el eje central sobre el cual giraron las políticas de salụd.

Si bien su hegemonía no se vio alterada, la importancia de los proyectos alternativos y las sólidas críticas a la función social que cumplía obligaron a modificar aspectos importantes tanto de su estructura como en su vida interna. Un interesante ejemplo de ello fue la reconversión del Hospital Rawson en Hospital Mixto (9).

El hecho de que el Hospital se haya convertido con la creación de la Asistencia Pública en un engranaje más de una estrategia de control capilar de la sociedad - a pesar de la campaña previa tendente a su sustitución y/o limitación- no impidió la supervivencia de muchos de sus problemas más graves. Esta aparente contradicción muestra los límites de la utopía higienista y la insuficiencia de aquella formación -tal como Raymond Williams define el término- de médicos-políticosfuncionarios a la hora de "poder» aplicar sus proyectos, aun en instituciones orientadas por ella misma (10).

A la continuidad del hospital en sus sentidos etimológicos de hospedería y coto, correspondió también una continuidad en la índole de 
sus problemas (11): la escasez de camas siguió siendo constante y el rechazo de pacientes graves una cuestión cotidiana. Situación a la que hacía referencia el periódico La Prensa en 1884 al comentar que: «más de una vez hemos dado cuenta de enfermos que han muerto sin los auxilios de la ciencia, rechazados de los hospitales por no haber camas" (12).

El hacinamiento en los hospitales fue un problema permanente y de difícil solución en este período. Su remodelación y la construcción de nuevas salas a partir de mediados de la década de 1890 sólo permitieron atenuar en parte esas duras condiciones de habitabilidad. Este hecho fue corroborado por una comisión encargada de estudiar la problemática hospitalaria, que concluyó que el estado de los hospitales «no basta para satisfacer las necesidades de la población menesterosa", señalando para el caso específico del Hospital San Roque que «la demanda de camas es indudablemente apremiante y exige casi constantemente la colocación en los corredores de un número bastante considerable de ellas sobrepasando muchas veces el número de enfermos que prudentemente podrían recibirse» (13).

Esta aparente brecha entre oferta y demanda obedecía en realidad a causas muy complejas. El sistema mismo en su funcionamiento histórico, priorizó siempre una intervención en última instancia, lo que llegó a condicionar en forma permanente la actitud de los pacientes potenciales, quienes, una vez llegado su turno, sólo podían repetir la norma. Se reforzaba así la vieja idea de que el hospital era la antesala de la muerte. Dada esta situación compleja que se retroalimentaba de manera permanente, cualquier intento de orientar los fines hospitalarios hacia otro tipo de pacientes, o variar los focos de atención, resultó de ardua aplicabilidad.

Los intentos de alterar este déficit hospitalario construyendo nuevas instalaciones fueron muchas veces fruto de la improvisación, lo que planteó problemas adicionales. Algunas iniciativas de envergadura emprendidas en tal línea fueron severamente criticadas por la corporación y las autoridades médicas, cuyos miembros se lamentaban de que «... en estas modificaciones no haya primado la previsión y la idoneidad necesarias para la mejor atención de los enfermos» (14).

En la cuestión hospitalaria, al igual que en toda la política referida al control de la pobreza y al saneamiento urbano en general, las desinteligencias entre las autoridades municipales y sanitarias por imponer sus disímiles criterios fueron una constante.

El caso del Hospital Muñiz, por ser quizás el más azaroso, es el que 
mejor condensa en sus primeros años de historia esta serie de desencuentros político-administrativos. Creado en 1882, le fue impuesto el nombre de Casa Municipal de Aislamiento en lugar del de «lazareto", denominación que venía siendo utilizada habitualmente hasta entonces para este tipo de instituciones. Dotado de cuarenta camas, nunca albergó a menos de noventa pacientes, hacinamiento que sólo pudo ser atenuado por la colocación de tiendas de campaña en los jardines. Tan malas llegaron a ser sus condiciones higiénicas, que hasta puso en peligro la salud del vecindario circundante, ya que fueron numerosos los casos de viruela observados en los habitantes de las zonas aledañas.

Por los motivos señalados, se dispuso el traslado del hospital en el año 1886, siendo notable el hecho de que la mudanza se llevara a cabo en forma íntegra sin el conocimiento de las autoridades médicas. Las quejas por la insuficiencia e imperfecciones del nuevo local acondicionado por el gobierno no se hicieron esperar, debido fundamentalmente a que «ni en la disposición de las salas ni en la condición del material, ni en la distribución de sus diversas dependencias, ni en nada en fin, había intervenido un criterio médico" (15).

Pronto tuvieron clara confirmación los reparos médicos: apenas inaugurado el nuevo local resultó insuficiente, por lo que hubo de construirse a su lado un precario armazón de hierro y madera destinado a la atención de mujeres.

En los años posteriores perduraron las tensiones y los desencuentros. En 1887, al asumir un nuevo intendente, Antonio Crespo, se aprobó un plan de alejar la Casa de Aislamiento del centro urbano, sin aceptar las sugerencias médicas que no lo consideraban fundamental ni prioritario. Se dio comienzo así a la construcción de otro nuevo local y, una vez más, no se informó del hecho a las autoridades médicas. Pero en esta oportunidad el cuerpo médico consiguió paralizar las obras, hasta tanto se aprobaran nuevos planos adaptados a sus sugerencias técnicas. Finalmente las obras se reemprendieron en 1894, interrumpiéndose varias veces por falta de fondos. En 1910 se encontraban aún inacabadas.

El Hospital Rawson, creado en 1868 para contener a los inválidos de la guerra del Paraguay y destinado en 1884 a hospital Mixto, tuvo una historia similar. Según testimonios de la época, todavía en 1908 (y en 1980) y a pesar de todas las refracciones a que fuera sometido, seguía teniendo «más apariencia de cuartel que de hospital moderno» (16).

Estos ejemplos, aplicables al conjunto de los hospitales de entonces, muestran que si en esta época puede hablarse de una cierta mo- 
dernización de los servicios, las desavenencias y tensiones jurisdiccionales, la improvisación y la insuficiencia de fondos fueron una constante negativa. La ineficacia de los hospitales para responder a las necesidades crecientes de la sociedad tuvo una base técnica pero, sobre todo, una motivación político-ideológica.

\section{V: LA MODERNIZACION HOSPITALARIA Y LOS «PEQUEÑOS PODERES»: CAMBIOS EN LA VIDA INTERNA DEL HOSPITAL}

1. El mundo de los pacientes: del «peregrinaje de los crónicos» a la atención de pacientes "externos»

El Hospital General típico del siglo XIX, a pesar de ciertas innovaciones técnicas, presentó escasas variantes con respecto a aquél de la época colonial. Inclusive puede decirse que en las primeras décadas del siglo, su funcionamiento interno llegó a deteriorarse en algunos aspectos, ya que la guerra, la anarquía social y las dificultades propias de la puesta en marcha de un estado independiente se tradujeron en una demora del reemplazo del Estado colonial en muchas áreas (17).

El Hospital, en toda esta época, funcionó como un depósito de pobres indiferenciados. En su seno no se planteaban acciones con miras a la reincorporación del individuo al medio social. El orden social del cual fue producto le reservó un ámbito de intervención específico: los indigentes crónicos. Esta situación estuvo asociada a la insuficiencia y falta de profesionalidad de su personal, especialmente aquel requerido para cumplir tareas subordinadas, que era reclutado en parte entre los mismos enfermos. Un caso típico fue el de Benjamín Sierra, quien, clasificado como «loco furioso", resultó enviado por la policía para que fuese «encerrado en el Hospital dedicándolo al trabajo en dicho establecimiento» (18).

Puede considerarse entonces al Hospital General como una institución básicamente custodial, de acogida indiscriminada, que al mismo tiempo representó para muchos pacientes o para los «empleados forzados", una forma de exclusión social (19). En este último de sus múltiples aspectos puede decirse que el Hospital representó un continuum de reclusión junto a las cárceles y otros institutos penales.

Pero al mismo tiempo, el gran dilema era éste: a pesar de ser considerado socialmente como «último escalón antes de la muerte» (no sólo porque los pacientes llegaran ya desahuciados, sino también porque 
muchos morían por causas distintas a las que habían determinado su internación) con lo que aterrorizaba a los sectores populares, el Hospital General era muy utilizado por un amplio sector de "pobres de solemnidad", para fines exclusivamente propios -obtener una cama por la noche o un poco de alimento-. Es importante también tener en cuenta que este tipo de pobres eran en muchos casos enfermos crónicos imposibilitados para el trabajo.

Dentro del Hospital, usado en forma "privada" por el sector social aludido, el funcionamiento se veía afectado por la aparición de una «cultura hospitalaria» de densa trama, cuyos protagonistas se habían convertido en un verdadero contrapoder. Una importante proporción del personal debía destinarse al mero control disciplinario, no sólo de los pacientes sino también de casos particulares de trabajadores, como las menores condenadas por los jueces y que estaban siempre al borde de la fuga.

Tal situación puso al descubierto, a los ojos de la élite, lo inadecuado de una política de control social por la mera exclusión o «recogida» de pobres indiferenciados; lo que se imponía, pues, era una redefinición de los objetivos hospitalarios y una modernización de las funciones.

Los planes de modernización hospitalaria en el área de la internación de pacientes se encontraban con la traba que imponía aquella «cultura de los enfermos crónicos». Este problema reiterado ya había motivado la creación del Asilo de Mendigos que, entre sus funciones, preveía la de facilitar el descongestionamiento de las salas de los hospitales, lo que mostró una incipiente actitud clasificatoria (20).

Sin embargo, el fracaso del Asilo de Mendigos como proyecto innovador fue inmediato. Sus salas se vieron rápidamente atestadas de enfermos e indigentes crónicos y se convirtió en un centro más de reclusión indiscriminado. En consecuencia, la pregunta ¿qué hacer con los crónicos? siguió vigente. La idea de ampliar los servicios hacia un conjunto mayor de la población, y aumentar la «permeabilidad» social del hospital, se vio enfrentada con esa situación de indiscriminación y hacinamiento.

Durante este período, al atenuarse los niveles de miseria extrema de la población, el problema de los enfermos crónicos pasó en términos relativos a un segundo plano. Sin embargo, su solución no dejó de ser parcial, registrándose, como en todos los aspectos referidos a la salud pública, importantes marchas y contramarchas que frenaron la aplicación de los criterios médicos en vigor. 
En la década de 1880, la situación de esos enfermos-pobres crónicos, fue mala. La Asistencia Pública intentó paliar el problema en 1883, trasladando los enfermos crónicos que estaban en el viejo Hospital de Hombres al Hospital San Roque y al Hospicio de Las Mercedes. Al poco tiempo, con el afán de centralizarlos en un solo lugar, se los trasladó a un depósito construido ad hoc en la Casa de Aislamiento, aunque quedaron muchos en el Hospicio. La medida se mostró insuficiente y al poco tiempo otros enfermos crónicos volvieron a llenar las salas de los hospitales municipales. Los hospitales de las colectividades extranjeras y el de la Sociedad de Beneficencia, paliaron tal situación mediante una política de estricto control de la admisión. Esto motivó fuertes tensiones con las autoridades municipales, dado que muchos pobres crónicos eran en general inmigrantes extranjeros, rechazados por las instituciones creadas por sus propias colectividades (21). El caso de la Sociedad de Beneficencia y las enfermas crónicas era mucho más grave porque casi no existían servicios para mujeres dado el estricto monopolio que ejercía la sociedad sobre su atención (22).

Tal fue la gravedad de la cuestión que las autoridades sanitarias decidieron en 1885 crear un nuevo Hospital de Crónicos, el que fue clausurado en 1891, como consecuencia de la gran crisis económica. Estas limitaciones tuvieron como consecuencia una vuelta al crítico estado previo: el "peregrinaje de los enfermos crónicos», como se denominó en la época al tránsito de estos enfermos de un hospital a otro solicitando cama.

Una vez superada la crisis, y ya entrada la década de 1890 , los enfermos crónicos mejoraron relativamente su situación cuando se producía un estancamiento general de los servicios de salud. Esta mejora relativa no se debió a que se crearan facilidades específicas para ellos, sino a que aprovecharon la ampliación general, aunque anárquica, de los hospitales en ese momento. Puede pensarse en consecuencia que esa mejora relativa, se dio en realidad en detrimento de otro tipo de enfermos hacia los cuales habían sido dirigidos originariamente esos servicios.

Durante el período reseñado se produjo, con referencia a los pacientes, un cambio en los focos prioritarios de atención. Los crónicos y los pobres indiferenciados, de a poco y con esfuerzo, dejaron su sitio preferencial. Este fue ocupado por otros enfermos, que permanecían ingresados por períodos de tiempo mucho más reducido. Varió, como se desprende de esto, el uso que se hizo del hospital, produciéndose una mayor rotación de pacientes, eliminándose en consecuencia aquella «cultura de los enfermos crónicos». 
Este viraje estratégico de los focos de interés del hospital permitió a su vez una cierta transformación en la actitud represiva del personal; ya que el férreo mantenimiento de la disciplina, que se creía necesario para sustentar sus antiguos e ineficaces objetivos, dejó de ser tan importante. Una parte del personal subalterno logró así independizarse de aquellas tareas y se ocupó sólo de cuestiones curativas y de la administración.

La instalación de consultorios externos comenzó a atraer también a distintos tipos de pacientes, los que en muchos casos requerían tratamientos prolongados pero que no hacían uso de las salas generales, aunque concurrían con cierta frecuencia al hospital. Este fue el aspecto en que el hospital representó una verdadera mejora y motivó un cierto aumento de la confianza que los sectores populares depositaron en él. En esto último influyeron fundamentalmente los avances de la bacteriología y la asepsia, que evidentemente redundaron en una mayor eficacia de los tratamientos.

\section{El mundo del personal}

\subsection{Médicos y Practicantes: Profesión y Jerarquias}

El uso distinto que los nuevos pacientes hicieron del hospital fue posible gracias a cambios importantes en su estructura interna.

Estas transformaciones fueron a su vez producto de un proceso de fuerte incidencia en la sociedad: la creciente «medicalización», con sus consiguientes cambios en los límites de lo considerado público y privado, y la "profesionalización» médica que se derivó de ello.

A partir de la década de 1870 , la aceleración de ese proceso llevó a los médicos a colocarse nítidamente, aunque con serias tensiones, a la cabeza de la estructura hospitalaria. Para llegar a tal situación de poder, debieron librar pequeñas batallas cotidianas, en apariencia pueriles, pero de vital importancia para profesionales que aspiraban a ejercer como corporación un efectivo monopolio sobre las decisiones públicas en el área de la salud (23).

El dominio del mundo interno de la «institución total» era considerado como una importante primera etapa para ampliarse luego al conjunto de la sociedad, verdadera paradoja de la «política práctica» de un grupo de médicos que influía en importantes grupos de poder con su insistencia continuada en la descentralización del control y las ayudas. 
La lucha que esa estrategia desencadenó fue un claro reflejo de aquella otra que, a nivel institucional y en el plano de las ideas, libraban los médicos con las Damas de la Sociedad de Beneficencia y con los funcionarios municipales. En la áspera vida cotidiana del hospital fueron las Hermanas de Caridad, y muchas veces las enfermeras «mercenarias», quienes litigaron con los médicos y en especial con los practicantes, por imponer sus criterios.

Los médicos comenzaron con este proceso a formar parte estable de la vida interna de los hospitales, a diferencia de épocas anteriores, en que concurrían casi exclusivamente para hacer consultas, y delegaban gran parte de las tareas en los practicantes, los que a su vez estaban subordinados a las Hermanas de Caridad.

A su vez el crecimiento de los servicios hospitalarios hizo necesario el aumento del número de sus médicos, que debieron, ante la mayor complejidad de las tareas a realizar, diferenciarse en categorías y cumplir más estrictamente las ya existentes. Se comenzó a exigir así que algunas tareas ejecutadas por practicantes fueran realizadas por médicos diplomados, reservándose para los primeros la exclusiva tarea de ayudantes. El médico director, autoridad suprema del hospital, pasó a desempeñar en la generalidad de los casos sólo esa función y no como antes, cuando dividía su tiempo entre las tareas de organización y las de médico de sala. Se creó una nueva categoría, la de médico agregado, quien, nombrado a petición del médico de sala, ejecutaba tareas bajo su coordinación.

Las funciones de los practicantes según sus respectivas categorías fueron cumplidas estrictamente. Se imposibilitó y se prohibió que los que tenían las materias aprobadas para ser practicantes mayores, siguieran ejerciendo indefinidamente funciones de practicantes menores por falta de vacantes u otros motivos, lo que resentía bastante el servicio.

Una cuestión que en el mediano plazo iba a ser motivo de discusiones fue el hecho de que, en general, ningún médico recibiera remuneración alguna por su trabajo en los hospitales, con la excepción de aquellos que prestaban servicio en la Casa de Aislamiento o en otros hospitales de enfermedades infecto-contagiosas.

Dos concepciones profesionales aún no totalmente discernibles en su antagonismo daban impulso a cada una de las posturas en que se dividía la opinión médica respecto a la tan espinosa cuestión de la remuneración en los hospitales. Un importante sector abogaba por una creciente «mercantilización» de la profesión médica; otro, en cambio, seguía identificando al médico con la figura del «filántropo universal». 
Esta fuerte ambivalencia que, a medida que se fue acercando el nuevo siglo, caracterizó cada vez más a la corporación médica, tuvo gran peso en el destino hospitalario. Mientras muchos de sus miembros criticaron duramente la política de no remuneración en los hospitales, aduciendo que resentía su buen funcionamiento, otros la consideraban adecuada, dado que, como el médico se debía fundamentalmente a su clientela, sus intervenciones en el hospital eran su aporte a la comunidad $\mathrm{y}$, por lo tanto, debían ser gratuitas.

Años más tarde, ante el claro triunfo de la corriente "mercantilista", Nerio Rojas, que al igual que los higienistas era un firme sustentador de la medicina como faz técnica de la filantropía, opinaba en una conferencia en el Círculo Médico Argentino que «... la vida porteña se ha caracterizado por un mercantilismo impresionante... esto es lo que ha pervertido a la profesión de médico. El espíritu médico ha sufrido mucho la influencia de esa frivolidad de la vida en la sociedad argentina, especialmente de la vida porteña» (24).

Según aquellos argumentos, la evolución en los criterios con que los médicos definieron su actividad afectó negativamente al desarrollo del hospital público en el período estudiado.

\subsection{Enfermeras y damas de caridad: el eslabón más débil}

El aumento y mejora de los aspectos médicos del hospital, se debía complementar - según los proyectos vigentes- con la introducción paulatina de la enfermera profesional, dotada de la necesaria preparación técnica.

Esta alteración en el viejo sistema del trabajo subalterno, elemento importante en los planes tendentes a ofrecer un servicio más eficaz y planificado, fue, por causas de muy distinto orden, de concreción difícil. Como consecuencia de ello, este tipo de personal - siguiendo una trayectoria muy distinta a la de los médicos y practicantes- no llegó a tener nunca la incidencia fuertemente renovadora que se esperaba de él.

Durante una parte importante del siglo XIX las tareas subalternas en los hospitales fueron responsabilidad de un conjunto heterogéneo de personas reclutadas de las maneras más diversas.

Las enfermeras profesionales, "personal mercenario" como se las llamaba en la época, eran escasas y no tenían ninguna preparación técnica: por estas razones su tarea específica se redujo al servicio doméstico y al mantenimiento de la disciplina. 
Una parte no desdeñable de las tareas menores era realizada por los mismos pacientes, hecho corroborado por las frecuentes alusiones de las crónicas contemporáneas a la actividad de dementes barriendo pisos y a la de otros pacientes doblando vendas.

Personas detenidas por la policía o condenadas por los jueces engrosaron en determinados casos las plantillas de empleados hospitalarios. Este fue el destino de Matilde Díez, de quien el juez de Paz de Bragado solicitaba al jefe de Policía que «se sirva destinarla por un tiempo al Hospital de Mujeres... por corrección de su mala y escandalosa conducta, pues esta mujer siendo casada, no hay forma que se sujete a su marido y tiene escandalizado a todo el vecindario».

El caso de la parda Petrona Alcorta, presa por ratera en la cárcel de mujeres, a quien se trasladó destinándola «a seis meses de reclusión al servicio del Hospital de Mujeres» (25) muestra también cómo en situaciones especiales o ante necesidades perentorias del servicio se recurría al trabajo forzado de personas detenidas en instituciones penitenciarias.

Lo mismo sucedió con las menores condenadas por los jueces, que llegaron a convertirse en una presencia típica de las salas de los hospitales. En las instituciones de la Sociedad de Beneficencia su trabajo como enfermeras se hizo necesario aun en los primeros años del siglo $\mathrm{XX}$.

La vieja idea de modificar los fines hospitalarios y reorientar su práctica, dio impulso a la iniciativa de introducir en el país a las Hermanas de Caridad, que se hicieron cargo en forma paulatina de importantes aspectos del servicio de asilos y hospitales. Para ello tuvieron que vencer la enconada resistencia de importantes sectores, tanto políticos como de funcionarios, quienes no dejaron en ningún momento de criticar su capacidad técnica y su idoneidad para ocupar puestos administrativos.

La instalación permanente de las Hermanas de Caridad en asilos y hospitales, en reemplazo de algunas de las antiguas categorías de enfermeras y domésticas, fue un símbolo de la voluntad política de diferenciar -más en forma teórica que real- entre la tarea específica de cuidar la salud de los pacientes y la mera reclusión. Como tal, supuso un cambio, aunque muy gradual, en el funcionamiento interno de aquellas instituciones.

Con la creación de la Asistencia Pública, las autoridades sanitarias contemplaron con creciente interés la idea de proveer a los hospitales con personal subalterno idóneo. En 1885 su director elevó un proyecto 
de creación de una Escuela de Enfermeras, que fue desestimado por la corporación municipal (26). La iniciativa fue entonces desarrollada fuera del ámbito público por la doctora Cecilia Grierson en el Círculo Médico Argentino, hasta que, en 1892, su escuela pasó a depender de la Asistencia Pública por iniciativa de su director, Emilio Coni (27).

La incidencia social de esta Escuela se vio seriamente limitada, sin embargo, por su escaso número de egresadas. No pudo por tanto mejorar la capacidad técnica del conjunto de las enfermeras, hecho que se pensaba que podría ocasionar un cambio radical en la atención hospitalaria.

En esto último influyó en forma decisiva la ineficaz política de personal adoptada tanto por la Intendencia Municipal como por la Sociedad de Beneficencia. Un intercambio de notas entre la Dra. Cecilia Grierson y la dirección del Hospital Rivadavia, administrado por la Sociedad de Beneficencia, arroja luz sobre la cuestión. Dicha doctora, que estaba dictando una serie de cursillos para empleados de la institución, solicitó a las autoridades que éstos se hicieran obligatorios a la totalidad del personal. Su petición le fue denegada, con el argumento de que si todas las enfermeras adquirían conocimientos técnicos el hospital iba a quedar acéfalo, puesto que las que asistían al curso dejaban luego la institución (28).

El escaso prestigio social de la profesión de enfermera, lo exiguo de los salarios pagados y las malas condiciones de trabajo hicieron de ella una profesión poco atractiva, hecho decisivo en el constante mal funcionamiento de los hospitales en el área de los servicios subalternos.

Penna y Madero, dos de los más prestigiosos médicos de la época, señalaron, corroborando aquellas afirmaciones, que las enfermeras de entonces eran sólo "sirvientas de hospital por las tareas que desempeñan», y agregaban que "tampoco puede pretenderse mejor clase de gente si se tiene en cuenta las pésimas condiciones de que se las rodea" y que "hasta el basurero es mejor remunerado» (29).

Ante la incapacidad administrativa y la falta de una suficiente voluntad política para cambiar radicalmente la situación de los trabajadores subalternos del hospital, las Hermanas de Caridad siguieron ejerciendo su trabajo en hospitales y asilos. Es necesario aclarar, sin embargo, que a pesar de su continuidad, con el paso del tiempo fue variando la índole de sus responsabilidades, especialmente en aquellas áreas en que se podía plantear un punto de incompatibilidad con la actividad de los médicos y en especial con la de los practicantes. Y con la profesionalización exigida, aunque defectuosamente implementada. 
Sin embargo, el gradual pero efectivo cambio en las atribuciones de las Hermanas no pudo evitar las asperezas y tensiones que, desde tiempo atrás, venían sucediéndose en el hospital. Así, por ejemplo, en 1904, La Prensa señalaba que «más de una vez han llegado a la redacción de este diario voces de protesta contra la preponderancia tiránica que asume el elemento religioso en los hospitales y establecimientos de caridad pública y privada», para agregar que "este modo de proceder de las Hermanas de Caridad origina con demasiada frecuencia choques y disidencias muy lamentables con los practicantes cuya autoridad se ve desconocida" (30).

La causa principal de la persistencia de aquellas asperezas y tensiones fue el mantenimiento, por parte de las Hermanas, de su papel tradicional como intermediarias entre la administración y el personal subalterno. Así podía leerse en 1904, con motivo de aquel conflicto «que tuvo revolucionado al Hospital de Clínicas y que amenazó hacerse extensivo a todos los hospitales» (31), que los médicos se quejaban de que su autoridad no era reconocida «no tan sólo por las Hermanas sino también por los peones y enfermeras influenciados por aquéllas». (32).

\section{CONCLUSIONES}

La sociedad argentina, en especial la de la ciudad de Buenos Aires, experimentó en la segunda mitad del siglo XIX un cambio social profundo.

La inmigración masiva, el aumento y"transformación de los sectores populares y el acelerado proceso de urbanización, motivaron el diseño de políticas concretas de control social que implicaron una mayor intervención estatal.

En ese proceso de creciente intervención estatal la estrategia fundamentalmente caritativa aplicada hasta entonces en el área de los cuidados de la salud y en la del control de la pobreza fue reemplazada, paulatinamente, por otras que implicaban un control «capilar» de la sociedad.

Sin embargo, la institución hospitalaria, eje fundamental de aquella vieja política caritativa, siguió cumpliendo por razones presupuestarias, administrativas y fundamentalmente ideológicas, un papel central en el nuevo sistema representado por la importancia creciente de la Asistencia Pública.

La continuidad del hospital, a pesar de las duras críticas a que fue sometido, limitó seriamente el alcance del nuevo sistema de salud idea- 
do por los más prominentes médicos de entonces. Esto implicó el fracaso, al menos parcial, de la estrategia de controlar a los sectores populares a partir de sus carencias, dado el carácter «estático» y poco flexible del hospital en cuanto «institución total».

A pesar de los intentos de renovar la vida interna del hospital, se mantuvo como telón de fondo la constante de sus viejos problemas: la élite porteña mostró siempre una escasa preocupación por los hechos vinculados a la reproducción de la mano de obra.

Mientras se siguieran renovando las cohortes de inmigrantes europeos este sector social hegemónico no cambiaría de actitud.

\section{NOTAS}

(1) Cortes Conde, R. y Gallo, E. (1977): La formación de la Argentina moderna, Buenos Aires, pp. 33-103.

(2) Romero, J. L. (1946): Las ideas políticas en Argentina, México, pp. 167-184.

(3) ONEGA, G. (1969): La inmigración en la literatura argentina 1880-1910, Buenos Aires, pp. $85-144$.

- Romero, J. L. (1973): Latinoamérica, las ciudades y las ideas, Buenos Aires.

- LOPEZ, L. (1875): La gran aldea, Buenos Aires.

(4) OszlaK, O. (1985): La formación del Estado Argentino, Buenos Aires, pp. 14-169.

(5) RAwSON, G. (1879): "Estudio sobre las casas de inquilinato de Buenos Aires», Es. critos Científicos, Buenos Aires, pp. 65-150.

(6) GonZÁlez, R. (1984): "Caridad y Filantropía en la Ciudad de Buenos Aires durante la segunda mitad del siglo XIX», Sectores populares y vida urbana, Buenos Aires, pp. 251-258.

(7) Coni, E. y Susini, T. (1878): "Organización de la Asistencia Pública», Revista Médico-Quirúrgica. Organo de los Intereses Médicos Argentinos, XV, 16, pp. 366-368.

- ConI, E. y SusinI, T. (1881): "Proyecto de organización de la Asistencia Pública», Revista Médico Quirúrgica. Organo de los Intereses Médicos Argentinos, XVII, 2, pp. 34-36 y XVIII, 3, pp. 57-61.

- SusinI, T. (1881): "Carta del Dr. Telémaco Susini», Revista Médico-Quirúrgica. Organo de los Intereses Médicos Argentinos, XVII, 24, p. 24.

- Meléndez, L. (1883): "Asistencia a domicilio», Revista Médico-Quirúrgica. Organo de los Intereses Médicos Argentinos, XVII 24, pp. 492-495.

(8) RAWSON (1879): p. 71

(9) MelÉndez, L. (1884): "Hospitales Mixtos», Revista Médico-Quirúrgica. Organo de los Intereses Médicos Argentinos, XVIII, 14, pp. 283-285.

(10) Williams, R. (1980): Marxismo y Literatura, Barcelona, pp. 37-43.

(11) CASARES, J. (1959): Diccionario ideológico de la lengua española, Barcelona, p. 222.

(12) Prensa (1885), 6 de enero.

(13) Memoria de la Intendencia Municipal de la Capital de la República correspondiente a 1887 presentada al $H$. Concejo Deliberante (1888), 2 vols., Buenos Aires, p. 82.

(14) Penna, J. y MAdero, H. (1910): La Administración Sanitaria y la Asistencia Pública de la Ciudad de Buenos Aires. Estudio de los servicios de higiene y beneficencia pública desde la época colonial hasta la presente, 2 vols., Buenos Aires, p. 231.

(15) Penna, J. (1910): Casa Municipal de Aislamiento Hospital Dr. Francisco Muñiz, Buenos Aires, p. 294. 
(16) Insúa Dorrego, P. (1910): Hospital Rawson, Buenos Aires, p. 280.

(17) Halperin Donghi, T. (1972): Argentina de la Revolución de Independencia a la Confederación Rosista, Buenos Aires.

- Casais de Corne, A.; Fernández, A. y González, J. (1977): Panorama Histórico de la Me. dicina Argentina, Buenos Aires, pp. 67-95.

(18) Archivo General de la Nación (A.G.N.), Sala X, Policía, 34-1-6.

(19) COE, R. (1970): Sociologia de la Medicina, Madrid, pp. 271-331.

(20) Castilla, R. (1910): Reseña histórica y descriptiva del Asilo de Mendigos, Buenos Aires.

(21) Memoria del Presidente de la Comisión Municipal al Concejo correspondiente al ejercicio de 1881 (1882), Buenos Aires, p. 386.

(22) Meléndez (1884)

(23) ConI, E. (1918): Memorias de un médico higienista, Buenos Aires, p. 80 y pp. 310-313.

(24) Rojas, N. (1928): La formación del espiritu médico, Buenos Aires, p. 50.

(25) A.G.N., Sala X, Policía 33-8-7.

(26) RAMOS MEJIA, J. (1886): «Informe anual de la Asistencia Pública correspondiente al año 1885", Memoria de la Intendencia Municipal de la Ciudad de Buenos Aires correspondiente a 1885 presentada al $H$. Concejo Deliberante, Buenos Aires, pp. 1-41.

(27) Grierson, C. (1893): «Escuela de Enfermeros y Enfermeras: Escuela de Primeros Auxilios», Anales de Higiene Pública y Medicina Legal, III, 2, pp. 89-96.

(28) A.G.N. (1892), Archivo de la Sociedad de Beneficencia, vol. 10, 12 de agosto de 1892.

(29) Penna y Madero (1910), p. 394.

(30) La Prensa (1904), 13 de enero.

(31) La Prensa (1904).

(32) La Prensa (1904). 